\title{
Understanding kids' social plays through the mindsponge mechanism
}

\author{
Manh-Tung Ho \\ Ritsumeikan Asia Pacific University \\ Beppu, Oita, Japan \\ September 07, 2021
}

Observing my daughter playing with her brother and friends helps me realize the immense number of social skills that we take for granted that we must learn, experience, and be taught. There are some many problems of learning that kids must solve in their simplest social encounter. For example, the problem of acculturation such as learning a new etiquette like they must speak certain phrases then they can eat; or the game-theoretical problem of reciprocation and retribution; or how to agree with each other on a set of rules for their spontaneous role-playing without even having enough words to describe all the rules, etc. [1-6].

The good thing about kids is that they help you, without knowing it, see everything as if for a first time. This is done through our sheer capacity to empathize with others, to put ourselves in our kids' shoes. If we just pay attention enough, each of us will feel our kid's happiness, calmness, frustration, shyness, feeling of being left out, excitement, and so on so naturally that we often forget how much time we spend replaying playing with our kids or seeing them playing in our head. The key ingredient in this wondrous process is about truly being mindful when being around our babies. Without the ability to be mindful, to be fully connected with the present moment, I guess we would not feel the full joy of raising our child and we would not understand why raising them teaches us so much. 
On a different note, when I try to conceptualize being a kid surrounded by the physical and social world he or she must learn about, the mindsponge mechanism seems to be a perfect fit. Kids, like us, are constantly in relation with their playmates (parents, family members, friends, etc.). They are constantly absorbing information, testing it, evaluating its cost and benefit, then imagining new scenarios, testing the information again, deducing the rules and counterfactuals from their plays, learning to accept and sometimes even rewriting the rules that govern their social interactions. This whole process is one of the most emblematic examples of the mindsponge mechanism of information filtering. It contains all crucial elements of the mindsponge model: core set of values, new information, trust evaluators via cost-and-benefit analysis, the 3D-creativity filtering process, comfort zone, cultural environment. For instance, imagining a kid playing with a friend who likes to be more adventurous than she is (core value and comfort zone). There is the element of whether family of the kid in question encourages her to take risk (cultural environment). There is element of her capacity to re-imagining the situation and how her friends and families can help her see things differently (3D filtering process). There is the element of whether the risk is acceptable given the expected gain, perhaps, a thrilling experience or a chance to form a stronger bond with this friend (cost-and-benefit analysis). There is also the element of her present choice will inform her future feeling and choice (the filtering process). All these elements can be formalized into a precise mathematical model, thus generating testable hypotheses, which for me, form the most important foundation for replicable social sciences studies [7-8].

Understanding how children learn and develop in the context of an ever-changing social landscape is one of the meaningful tasks of science. Incorporating new, culturally sensitive models of the mind into the toolkits of the social sciences and humanities is crucial for making progress.

\section{References}


1. Vuong, Q.-H., et al. (2019). Cultural evolution in Vietnam's early 20th century: A Bayesian networks analysis of Hanoi Franco-Chinese house designs. Social Sciences \& Humanities Open, 1(1), 100001. https://doi.org/https://doi.org/10.1016/j.ssaho.2019.100001

2. Vuong, Q.-H., et al. (2018). Cultural additivity: Behavioural insights from the interaction of Confucianism, Buddhism and Taoism in folktales. Palgrave Communications, 4(1), 143. https://doi.org/10.1057/s41599-018-0189-2

3. Vuong, Q.-H., et al. (2020). On how religions could accidentally incite lies and violence: folktales as a cultural transmitter. Palgrave Communications, 6(1), 82. https://doi.org/10.1057/s41599-020-0442-3

4. Vuong, Q. H. (2016) Global mindset as the integration of emerging socio-cultural values through mindsponge processes: A transition economy perspective. In: Kuada J (ed) Global Mindsets: Exploration and Perspectives. London: Routledge., 109-126.

5. Vuong, Q. H., \& Napier, N. K. (2015). Acculturation and global mindsponge: an emerging market perspective. International Journal of Intercultural Relations, 49, 354-367.

6. Vuong, Q.-H. (2021). The semiconducting principle of monetary and environmental values exchange. Economics and Business Letters, 10(3), 1-9.

7. Vuong, Q. H. (2018). The (ir)rational consideration of the cost of science in transition economies. Nature Human Behaviour, 2(1), 5-5. https://doi.org/10.1038/s41562-017-0281-4

8. Vuong, Q.-H. (2020). Reform retractions to make them more transparent. Nature, 582(7811), 149. doi: https://doi.org/10.1038/d41586-020-01694-X 
